\title{
Computing Support in Statistical Evaluation of Mathematics Teaching Effectiveness: Development of Students' Constructive Thinking
}

\author{
Miroslava Mihajlov Carević ${ }^{\text {; }}$ Milena J. Petrović ${ }^{2}$; Nebojša Denić ${ }^{2}$; Aleksandra Mitrović ${ }^{3}$ \\ ${ }^{1}$ Faculty of Mathematics and Computer Science, Alfa BK University, Beograd, Serbia, \\ miroslava.carevic.mihajlov@alfa.edu.rs \\ ${ }^{2}$ Faculty of Science and Mathematics, University of Priština, Kosovska Mitrovica, Serbia \\ milena.petrovic@pr.ac.rs; nebojsa.denic@alfa.edu.rs \\ ${ }^{3}$ Primary school Stevan Sremac, Belgrade, Serbia
}

\begin{abstract}
One of the main tasks in teaching mathematics is to develop students' constructive thinking. In order to effectively accomplish this task, it is necessary to make a good selection of instructional materials and teaching aids. In order to make good selection and improve the teaching of mathematics, it is, also, necessary to include a statistical analysis of the certain factors' impact that affect mathematics curriculum. For the purpose of this research, we used the software computational approach ANFIS (adaptive neuro fuzzy inference system) to determine the qualitative impact of several factors on improving students' ability to create constructive thinking.
\end{abstract}

\section{KEYWORDS}

constructive thinking, mathematics teaching, impact factors, educational software

\section{INTRODUCTION}

The twenty-first century, as the age of the widespread use of electronic information and communication technology (ICT), requires technologically educated people. Therefore, one of the main tasks of modern education is to introduce students to new technologies and to train them for their active use. An overview of the use of technological advances in mathematics teaching is presented in the paper [4] and [5]. Technological development has significantly changed teaching aids and placed new demands on teachers. Modern teachers must be prepared to use new teaching technologies [20]. By analyzing the implementation of ICT in Mathematics learning, the authors of the paper [1] pointed out that the lack of knowledge about the ways of employing modern technologies in mathematics curriculums, as well as the lack of adequate teacher training, represent a great obstacle in the successful implementation of ICT in teaching. 
Differences in the ways and amount of ICT implementation in rural and urban areas have also been observed [14].

In their research based on the statistical evaluation of the realization of mathematics teaching implementing computers, the authors of this paper [9] took into account 10 impact factors. The main goal of this research is to analyze the factors that influence the quality of mathematics teaching related to the level of knowledge achieved during one school year as well as at the final exam. To determine the qualitative impact of the selected factors on the performance of mathematics, a software-based computer approach, namely, the adaptive neuro fuzzy inference system, ANFIS, was used. The research showed that the percentage of students studying with educational software had the major influence on the average score on the final exam.

The effectiveness of learning mathematics implementing mathematical software packages is also a subject of investigation among many contemporary scholars. In the paper [18], geometry learning in the coordinate system was analyzed using the GeoGebra software package. The authors of the paper [24] examined the impact of GeoGebra on student achievement in trigonometry teaching. In the paper [17] was shown that dynamic geometry software (DGS) has inherent interpretive flexibility and mathematical potential for dynamic control. The combination of dynamic geometry, algebra, and calculus is presented in the paper [11], as well as the presentation of dynamic mathematics software to high school teachers [12]. In the paper [21], was also explored the GeoGebra efficiency in calculus classes with first year students. The results showed that students who used a computer and GeoGebra while learning succeeded to analyze and draw function graphs. In the paper [2] was shown that integrating ICT into teaching processes makes teaching effective and interesting, and that it also contributes to the development of students' active thinking by stimulating their creative thinking. Analysis of the opinion of the elementary school math teachers on the implementation of GeoGebra in mathematics teaching is also presented in paper [8].

In the process of learning mathematics and solving mathematical problems, visualization and representation of the problem situation are of great importance [3]. The authors of the paper [23] deal with the relationship between problem solving and knowledge creation in a visualizationbased environment. Visualization and its use on Whiteboard are also the subject of the analysis in the paper [22]. The study [6] depicted two ways of visualizing regularities among natural numbers and solving problems using observed regularity. The first method uses working with figurative numbers and the second method uses selected examples to develop a visual-logical approach to solving problems with a series of numbers.

Evaluation of the learning effectiveness in collaborative groups was also conducted. The study has shown that collaborative groups are more efficient in their work because group members help one another in learning, encourage each other, and with joined forces come to the knowledge and understanding of the problem [7]. Collaborative learning develops teamwork and responsibility in the workplace because each individual is responsible not only for their own learning but also for the learning of other group members [13]. In the papers [10] and [16], it was 
stated that computer-assisted teaching and studying in collaborative groups is one of the most advanced ways to improve learning and teaching.

Constructivism represents an approach to teaching and learning in which the student creates an opinion about new knowledge by linking it to already existing knowledge. Creating knowledge is done by interacting with other students and the teacher. In this context, students' collaborative work, exchange of their views, discussions and explanations are of great importance. Constructivism enhances students' intellectual development, replaces learning memory and it is a great alternative to traditional methods in education. The benefits of constructivism are highlighted in the paper [19].

Constructive thinking involves linking knowledge, observation of the laws among the elements, the use of observed patterns, visualization and representation problems.

The main goal of this research is to analyze the factors that impact the improvement of students' abilities in detecting regularity among numbers and solving problems with numerous sequences. Students' performance indicators are the results of the post-test research performed. The results of the pre-test of the conducted research showed a low level of readiness of students to find out the regularity among the numbers, expressed as a percentage less than $25 \%$. Therefore, we organized the introduction of students to selected examples for demonstrating lawfulness and to figurative numbers that abound in a multitude of laws. At the end of the research, students were tested and interviewed in order to gain insight into the effectiveness of the applied tool as well as the students' opinions on the selected factors.

Based on the current indicators, the following hypotheses can be made:

- If students are shown good examples that can be paradigms for detecting laws among numbers, their success in solving tasks with numerous sequences on post-test will be better;

- If the students' awareness of the visual-logical approach to solving mathematical problems is present, then their success at the post-test will be higher;

- If computers, educational software and other teaching innovations are applied in math classes, students' success in the post-testing will be higher.

\section{METHODOLOGY}

A major indicator of improving students' ability to detect regularity among numbers and to apply perceived regularity in solving tasks with strings of numbers is post-test success. There are several factors that impact student success. In this research, we analyzed the following factors:

1. The average number of points in the pre-testing;

2. Percentage of students who stated that practicing spotting laws among numbers is helpful in solving problems; 
3. Percentage of students who stated that working with figurative numbers and selected examples is interesting;

4. Percentage of the number of students for whom figurative numbers and selected examples help to identify the legality of the numbers;

5. Percentage of students who are motivated to learn applying innovation in teaching;

6. Percentage of students who wish to improve their skills to spotting law among numbers;

7. Percentage of teachers who use educational software in the classroom;

8. Percentage of teachers who use a visual-logical approach when solving problems;

9. Percentage of teachers who teach in the traditional way.

The data analyzed in this study was obtained from the survey conducted over the previous 5 years as well as through a questionnaire. The survey included a total of 2545 primary and secondary school students. The statistics include students' pre-test success and post-test success. The remaining data were collected via a survey questionnaire in primary and secondary schools. The obtained data were used for analysis using ANFIS procedure [15]

\section{RESULTS}

For all 9 factors, the ANFIS network evaluated the root mean square errors (RMSEs) as it is shown:

Factor 1, RMSE = 0.1886,

Factor 2, RMSE $=0.1864$,

Factor 3, RMSE = 0.1882,

Factor 4, RMSE = 0.1893,

Factor 5, RMSE $=0.0738$,

Factor 6, RMSE = 0.1853,

Factor 7, RMSE = 0.1324,

Factor 8, RMSE $=0.1895$,

Factor 9, RMSE $=0.1898$.

Factor 5 has the strongest influence on the average score in the post-testing, since its RMSE is the lowest. We can conclude that the percentage of students who are motivated to learn with innovation in mathematics teaching has the strongest influence on post-testing students' achievement. 
By combining two factors, the ANFIS Network has estimated that the following two factors have the strongest impact on student achievement in the post-testing:

Factor 4 and Factor 5, RMSE $=0.0672$.

Based on this assessment, we can conclude that the results of the students' post-testing ability in identifying laws among numbers and solving multiple-task problems will be better if students are motivated to learn applying innovation in teaching (Factor 5) and are of the opinion that figurative numbers and the examples selected help to identify the laws among the numbers (Factor 4)

By combining three factors, the ANFIS Network evaluated that the following three factors have the strongest impact on the student's average post-testing score:

Factor 8, Factor 4 and Factor 5, RMSE $=0.0568$.

Based on the results, it can be concluded that the average number of points in the post-testing will be higher if teachers implement a visual-logical approach in solving problems (Factor 8), students are motivated to learn with innovation in teaching (Factor 5) and believe that figurative numbers and the selected examples help to identify the regularity among the numbers (Factor 4).

\section{DISCUSSION}

The results obtained in this study show that students' motivation to learn applying innovation in mathematics teaching has the major influence on the average number of points on the posttesting of students' ability to detect regularities among numbers and to solve problems using the observed regularity. This is an evidence of our third hypothesis in the paper. The result is not a novelty. For some time, information and communication technologies have had a great influence in the teaching and learning process. The students are undoubtedly interested and very keen on the application of innovative teaching aids.

In addition to motivating students to learn applying innovations in teaching, learning figurative numbers and selected examples has an important role to play in the test of student competence in identifying patterns among numbers. This confirmed our first hypothesis in the study. The result obtained is not new because paradigms play an important role in the process of learning and solving problems.

The third impact factor that, in combination with the previous two, has the strongest impact on student achievement in the set requirements, was the percentage of teachers who use a visuallogical approach to solving problems in the classroom. This confirms the third hypothesis of this study. If teachers use a visual-logical approach while solving tasks, students will see the procedure and apply it in their work. However, this factor has the effect of improving students' ability to perceive laws among numbers if there are two factors mentioned above: motivation to learn using innovation in the lectures and carefully selected examples-paradigms for detecting 
law among numbers. It can be concluded that there will be an improvement in the students' ability to perceive laws among numbers and to solve multiple-string problems if there is educational software that leads to a visual-logical approach to solving problems and to detect laws among numbers.

\section{CONCLUSION}

Since mathematics teaching could be reduced to training students in mastering formulas and algebraic procedures, there is a need to develop a visual-logical approach in order to solve mathematical problems. It is also extremely helpful to familiarize students with examples that can be paradigms for many other examples and tasks. Observing laws, associating a given problem with a problem whose solution is known, generating opinions on new information and concepts by linking it to existing knowledge - all of these develop constructive thinking. The results of this study confirm that an educational software application, with well-chosen examples for visual-logical approach to problem solving, could produce the best results in improving students' ability to detect laws and to solve problems by applying perceived regularity. Future directions for the research should be directed toward examining educational software to develop constructive thinking.

\section{REFERENCES}

1. D. D. Agyei and J. Voogt, ICT use in the teaching of mathematics: Implications for professional development of pre-service teachers in Ghana. Educ. Inf. Technol. 16 (2011), 423- 439.

2. M. Allegra, A. Chifari and S. Ottaviano, ICT to train students towards creative thinking, Educational Tehnology \& Society, 4 (2001), 48-53.

3. A. Arcavi, The role of visual representations in the learning of mathematics. Educational studies in mathematics, 52(2003), 215-241.

4. G. Bozkurt and K. Ruthven, Classroom-based professional expertise: A mathematics teacher's practice with technology. Educational Studies in Mathematics, 94(2017), 309-328.

5. A. Bray and B. Tangney, Technology usage in mathematics education research-A systematic review of recent trends. Computers \& Education, 114(2017), 255-273.

6. M. M. Carević, M. Petrović and N. Denić, Figurative Numbers Contribution in Perceiving the Legality in Numerous Strings Tasks and Long-term Memory of Numerous Data. EURASIA Journal of Mathematics, Science and Technology Education, 15(2019), 4.

7. M. Dooly, (Ed.) Telecollaborative language learning: A guidebook to moderating intercultural collaboration online. Peter Lang, (2008). 
8. B. K. Doruk, M. Aktumen and C. Aytekin, Pre-service elementary mathematics teachers' opinions about using GeoGebra in mathematics education with reference to 'teaching practices'. Teaching Mathematics and Its Applications, 32(2013), 140-157.

9. S. Gavrilović, N. Denić, D. Petković, N. V. Živić and S. Vujičić, Statistical evaluation of mathematics lecture performances by soft computing approach. Computer Applications in Engineering Education, 26(2018), 902-905.

10. E. A. Gomez, D. Wu and K. Paserini, Computer-supported team-based learning. The impact of motivation, enjoyment and team contributions on lerning outcomes, Computers \& Education 55(2010), 378-390.

11. M. Hohenwarter and K. Fuchs, Combination of dynamic geometry, algebra and calculus in the software system GeoGebra. In Computer algebra systems and dynamic geometry systems in mathematics teaching conference (2004, July), (pp. 3810-193).

12. J. Hohenwarter, M. Hohenwarter and Z. Lavicza, Introducing dynamic mathematics software to secondary school teachers: The case of GeoGebra. Journal of Computers in Mathematics and Science Teaching, 28(2009), 135-146.

13. M. Laal and S. M. Ghodsi, Benefits of collaborative learning. Procedia-Social and Behavioral Science, 31( 2012), 486-490.

14. E. Loong, B. Doig and S. Groves, How different is it really?-rural and urban primary students' use of ICT in mathematics. Mathematics Education Research Journal, 23(2011), 189-211.

15. D. Petković, M. Gocić and S. Shamshirband, Adaptive neuro-fuzzy computing technique for precipitation estimation. Facta Universitatis, Series: Mechanical Engineering, 14 (2016), 209218.

16. P. Resta and T. Laferrière, Technology in support of collaborative learning. Educational Psychology Review, 19(2007), 65-83.

17. K. Ruthven, S. Hennessy and R. Deaney, Constructions of dynamic geometry: A study of the interpretative flexibility of educational software in classroom practice. Computers \& Education, 51(2008), 297-317.

18. R. A. Saha, A. F. M. Ayub and R. A. Tarmizi, The effects of GeoGebra on mathematics achievement: enlightening coordinate geometry learning. Procedia-Social and Behavioral Sciences, 8(2010), 686-693.

19. M. Schcolnik, S. Kol and J. Abarbanel, Constructivism in theory and in practise. In English Teaching Forum, 44(2016), No.4, pp. 12-20.

20. M. Tabach, A mathematcs teacher's practice in a tehnological environment: A case study analysis using two complementary theories, Tehnology, Knowledge and Learning, 16(2012), 247265.

21. D. Takači, G. Stankov and I. Milanovic, Efficiency of learning environment using GeoGebra when calculus contents are learned in collaborative groups. Computers \& Education, 82(2015), 421-431.

22. J. Walny, S. Carpendale, N. H. Riche, G. Venolia and P. Fawcett, Visual thinking in action: Visualizations as used on whiteboards. IEEE Transactions on Visualization and Computer Graphics, 17(2011), 2508-2517.

23. M. Wang, B. Wu, Kinshuk, N. S. Chen and J. M. Spector, Connecting problem-solving and knowledge-construction processes in a visualization-based learning environment, Computers \& Education, 68(2013), 293-306.

24. Y. Zengin, H. Furkan and T. Kutluca, The effect of dynamic mathematics software geogebra on student achievement in teaching of trigonometry. Procedia-Social and Behavioral Sciences, 31 (2012),183-187. 